\title{
A RAIVA E AS EMOÇÕES EM ARISTÓTELES: AS ESTRATÉGIAS DO STATUS
}

\author{
DAVID KONSTAN* \\ Brown University \\ (Providence, EUA)
}

\begin{abstract}
RESUMO: Esse artigo pretende examinar a concepção aristotélica de raiva conforme exposta no segundo livro da Retórica. Isso feito, buscar-se-á determinar como o filósofo a situa no contexto geral de sua teoria das emoções, levando em conta o enfoque atual da questão.
\end{abstract}

PALAVRAS-CHAVE: Aristóteles; Retórica; teoria das emoções.

Em uma turma de graduação, à qual indiquei o segundo livro da Retórica de Aristóteles (traduzido), eu pedi a cada um dos estudantes que elaborasse uma lista de dez emoções. Foi notável a pequena interseção que houve entre os inventários deles e as paixões analisadas por Aristóteles. A raiva era proeminente em ambos os conjuntos, mas, além disso, havia pouca concordância. Entre as emoções sugeridas pelos estudantes, as quais não figuram na discussão aristotélica, estavam: padecimento, pesar, tristeza, felicidade, ciúme, saudade e solidão. Nenhum dos estudantes, por outro lado, mencionou piedade, inveja, dignação, vergonha, amabilidade, confiança, rivalidade ou benevolência. A diferença entre o catálogo de Aristóteles e o conjunto composto a partir das listas de meus alunos é indício de dois pontos de vista diferentes sobre as paixões. Ela também sugere que mesmo no caso da raiva, onde ambas as listas coincidem, é provável que a concepção de Aristóteles divirja substancialmente daquilo que nossa própria intuição poderia sugerir.

Nesta conferência, eu examino em detalhe a explicação aristotélica da raiva, que é, de fato, bem diversa, em muitos aspectos, das noções modernas. Esta primeira parte é, necessariamente, a mais técnica. Em seguida, tento situar o tratamento que Aristóteles dá à raiva no contexto de seu entendimento das emoções em geral. Não pretendo, nesta ocasião, investigar os princípios que poderiam explicar o elenco das 
emoções propostas por meus alunos, embora tenha a impressão de que as emoções que eles selecionaram sejam algo parecidas com estados internos de sentimentos, mais do que respostas ao comportamento - exceto aquelas que são instâncias de relações amorosas.

\section{A explicação aristotélica da raiva}

Aristóteles define raiva como "um desejo, acompanhado de dor, de vingança percebida, em razão de uma desconsideração percebida em relação a um indivíduo ou seu próximo, vinda de pessoas das quais não se espera uma desconsideração" (2.2.1378a31-33). Por que "acompanhado de dor"? Provavelmente, esse elemento é exigido pela definição de pathê que Aristóteles ofereceu um pouco antes: "Que as emoções sejam todas aquelas coisas em razão das quais as pessoas mudam seus pensamentos e discordam em relação aos seus julgamentos, sendo aquelas acompanhadas de dor e prazer, por exemplo raiva, piedade, medo e todas as outras coisas semelhantes e seus contrários" (2.1.1378a20-23). Aristóteles não pretendia que essa fosse uma rigorosa ou exaustiva explicação da natureza dos pathê. Claramente, ela é destinada a servir ao seu presente propósito, que é o de instruir o orador em como manipular as emoções de sua audiência; daí a ênfase no efeito das emoções sobre o julgamento (kriseis), no sentido de um veredicto ou decisão. A introdução de dor e prazer aqui pode ser um modo sucinto de distinguir as respostas emocionais daquelas baseadas exclusivamente na razão ou nos entimemas, um tópico que Aristóteles tratou com especial cuidado no primeiro livro da Retórica.

Dor e prazer, em si mesmos, não contam, para Aristóteles, como emoções. Mais precisamente, eles são sensações ou aisthêseis. Uma sensação dolorosa pode surgir ou como resultado de uma percepção direta ou, ainda, por meio de uma phantasia, isto é, através da recordação ou antecipação de algo percebido. Nas palavras de Aristóteles: "uma vez que o sentir prazer ocorre na percepção de alguma experiência [pathos] e a phantasia é um tipo fraco de percepção [aisthêsis], alguma phantasia do que alguém se lembra ou espera sempre ocorre a uma pessoa quando ela se lembra de algo ou espera alguma coisa... Assim, é necessário que todos os prazeres ou estejam presentes na percepção ou surjam quando são lembradas coisas que aconteceram ou quando se espera por coisas que acontecerão" (1.11.1370a27-34).

Qual é a dor que acompanha a raiva? Parece razoável supor que ela resulta de uma percepção direta de algo prejudicial ou desagradável, mais do que da memória ou antecipação, como é o caso, por exemplo, do medo, que Aristóteles define como "sur- 
gindo a partir da phantasia de um mal futuro que é fatal ou prejudicial" (ek phantasias mellontos kakou phthartikou ê lupêrou, 2.5.1382a21-22). Se isso é assim, a dor da raiva diferiria do prazer que está, também, associado a essa emoção e que deriva do desejo de vingar a desconsideração que foi sofrida, pois esse desejo é acompanhado pela expectativa (elpis) de sua realização, a qual consideramos possível (caso contrário, nós não estaríamos experimentando a emoção que Aristóteles define como raiva). Aristóteles oferece uma segunda razão para o prazer que nós sentimos quando enraivecidos, a saber, que meditando sobre a vingança em nossas mentes (dianoia), a phantasia que assim surge instila prazer análogo ao que sentimos nos sonhos (2.2.1378b1-9). Eu não estou certo se entendo a diferença entre as duas razões: a expectativa de vingança é prazeirosa, eu imaginaria, por causa da impressão que a acompanha. Em todo caso, a dor conectada com a raiva, diferentemente do prazer, parece derivar, à primeira vista, não da phantasia de um dano ou aborrecimento passado ou futuro, mas da percepção de alguma coisa que está presente. Não obstante, é importante notar as expressões paralelas que Aristóteles emprega na definição de raiva: "uma vingança percebida [phainomenês] em razão de uma desconsideração percebida [phainomenên].” O verbo phainomai não é tão técnico quanto phantasia, mas, à luz da discussão que se segue, não é descabido entender phainomenês timôrias como "vingança imaginada." A desconsideração é, então, também imaginada, no sentido de ser mais lembrada do que antecipada? É possível, parece-me, que Aristóteles esteja pensando na raiva como um sentimento durável, que surge em um momento determinado como uma aisthêsis, mas sobrevive por meio de uma reflexão subseqüente ou uma recordação da desconsideração recebida.

Eu tenho assumido que a "desconsideração percebida" que origina a raiva -seja ela imediata, recordada ou interpretada -- é desagradável por si mesma (do mesmo modo que o pensamento de vingança é agradável) e daí uma fonte de dor. $\mathrm{O}$ problema com essa interpretação, no entanto, é que ela parece fazer a expressão "acompanhada de dor" redundante. Talvez Aristóteles pretenda indicar que nem toda ofensa, mesmo se percebida como tal e associada a um desejo de vingança, é necessariamente uma fonte de raiva. Se nós estamos imaginando que outro tipo de reação Aristóteles poderia ter em mente, podemos olhar mais adiante sua discussão sobre o ódio, que ele distingue da raiva, dentre outras maneiras, observando que "um é acompanhado de dor, enquanto o outro não é acompanhado de dor, pois quem está com raiva sente dor, mas quem odeia não" (2.4.1382a12-13: cf. Política 5.8.1312b25-34). Ódio é uma reação ao que é prejudicial ou vicioso (kakon) em geral, não apenas à desconsideração, e certas formas de prejuízo -- Aristóteles destaca o vício mesmo (kakia), por exemplo a injustiça ou estupidez - são praticamente imperceptíveis (hêkista aisthêta, 2.4.1382a9-11), razão por que não são particularmente dolorosas. Uma vez 
que o despeito (epêreasmos) -- que é classificado como um dos três tipos de desconsideração no tratamento aristotélico da raiva (2.2.1378b14) - é, também, citado como uma das causas do ódio ou inimizade (2.4.1382a2), pareceria que a desconsideração pode produzir não apenas raiva, mas, ainda, um tipo de hostilidade que não é necessariamente acompanhada por dor e, portanto, incompatível com a raiva. Isso quer dizer que a desconsideração, nesse caso, não é em si mesma dolorosa ou desagradável? Creio que podemos assumir que qualquer desconsideração é desprazível. No entanto, a característica ou expressão primária de raiva (oposta a sua causa), na definição de Aristóteles, é o desejo de vingança e é esse, de acordo com Aristóteles, que deve, no caso da raiva, ser acompanhado pela dor. Eu estou inclinado a pensar que esse desejo é tanto agradável, à medida que ele envolve a consumação antecipada da vingança, quanto doloroso, à medida que ele é acompanhado, também, pela recordação ou pensamento sobre a desconsideração que motivava o desejo. É, então, a persistência da dor, derivando da desconsideração (originariamente dolorosa), que acompanha e, de fato, inspira o desejo de vingança e o constitui como raiva.

Que a raiva deva, para Aristóteles, surgir especificamente e, de fato, exclusivamente de uma desconsideração, mais do que de outros tipos de prejuízo deliberado que outra pessoa poderia infligir, é notável e irá ocupar nossa atenção nas páginas seguintes. Uma desconsideração é um evento social complexo e requer uma considerável capacidade de julgamento a fim de ser reconhecida ou percebida como tal. De fato, Aristóteles deixa isso claro na própria definição de raiva, que uma desconsideração como tal -- uma particular observação ou gesto, por exemplo -- não é a causa da emoção; mais precisamente, deve ser a desconsideração por parte de alguém de quem não se espera que seja ou a quem não convém ser o seu autor (prosêkôn). Nós retornaremos brevemente à questão de que precisamente é isso que poderia fazer com que um indivíduo cometesse tal ofensa. No momento, podemos nos ater ao elemento de discriminação ou avaliação, envolvendo no mínimo a habilidade de fazer a distinção entre pessoas que têm ou não o direito de falar ou agir de determinados modos, que está implícito na definição aristotélica da raiva, pois está claro que a raiva, para Aristóteles, é qualquer coisa, exceto um reflexo automático ou instinto.

\section{Emoções e cognição}

Há mais de duas décadas que estudiosos começaram a prestar atenção mais séria ao aspecto cognitivo da teoria das emoções em Aristóteles. Esse desenvolvimento coincidiu com uma mudança de perspectiva nas modernas explicações filosóficas, 
biológicas, antropológicas e psicológicas das emoções, que nos anos recentes têm prestado cada vez mais atenção ao papel da cognição. De fato, tem havido mesmo um esforço de definir as emoções completamente em termos de processos cognitivos. Tudo isso está em agudo contraste com a polarizada oposição entre razão e paixão que tem sido característica da filosofia pós-cartesiana e continua a prevalecer no pensamento popular. A visão de que as emoções são irracionais coincide com a tendência, que começou no fim do século dezenove, a explicar as emoções inteiramente em termos físicos, ignorando, desse modo, o elemento de julgamento completamente. O artigo "Emotion", parte um do texto "Human Emotion and Motivation", na The New Encyclopedia Britannica (1986), de Endre Grastyán, Professor de Fisiologia na Medical University of Pécs, na Hungria, está preocupado -- como alguém poderia esperar a partir da especialidade do autor quase exclusivamente com as bases orgânicas das emoções. O Dr. Grastyán escreve (p.348): "A investigação sobre o assim chamado fenômeno emocional está sendo amplamente apontada em direção à evidência biológica objetiva." Observando que o último tratado de Charles Darwin, The Expression of the Emotions in Man and Animals (1955; o original é de 1872), "teve uma profunda influência na sistematização da pesquisa sobre a emoção." Grastyán explica que estudos subseqüentes têm se concentrado em reações visível e ostensivamente adaptativas como agressão, susto e adulação assim como reações de fadiga, choro e riso involuntários, padrões de sono e coisas semelhantes -- comportamentos que dificilmente são qualificados como emoções no entendimento aristotélico do termo. Pesquisadores começaram, também, a explorar as operações dos sistemas nervosos simpático e parasimpático: o pioneiro aqui foi o fisiologista Walter B. Cannon, que enfatizou o papel das emoções nas reações de luta e de fuga. Sintomas tais como a taxa de batimentos cardíacos, níveis de açúcar no sangue, produção de adrenalina e seratonina, reação galvânica da pele e respiração foram cuidadosamente medidos. Finalmente, a função das emoções foi associada a impulsos básicos, níveis de energia e esforços apontados em direção à realização bem sucedida de objetivos: lembremos que a segunda parte do artigo da Encyclopedia Brittanica trata do tópico da motivação. Os herdeiros desse programa de pesquisa têm sido, por um lado, os estudos da expressão da emoção, empreendidos por Paul Ekman e seus associados (por exemplo Ekman 1992) e, por outro, a recente moda de psicologia evolutiva, representada por uma leva de volumes populares, muitos de valor científico duvidoso.

Aristóteles, também, sustenta que as emoções têm uma base física no organismo (confira De Anima 1.1.403a16-b2, especialmente 403a25: ta pathê logoi enuloi eisin), mas ele não reduz as emoções a estados materiais tais como temperatura do sangue em torno do coração. Na Retórica, naturalmente, ele está interessado nas paixões acima de tudo por seu papel na persuasão, mais do que estímulos à ação; por conseguinte, ele 
A raiva e as emoções em Aristóteles: as estratégias...

enfatiza os componentes racionais e valorativos dos pathê, que podem ser influenciados pelo discurso. Mas o aspecto cognitivo é indispensável para uma explicação das paixões como tal, apesar da confiante alegação de Lewis, Amini e Lannon (2000, p. 42) de que "a maioria das emoções não requer em absoluto pensamento."

A fragilidade na visão psicológica da raiva é evidente na seguinte situação hipotética. Uma mulher é violentamente empurrada pelas costas. Instintivamente seus músculos ficam tensos e seu coração bate mais rápido. Ela pode correr para escapar ou defender-se, talvez agressivamente, batendo no seu ofensor. Mas ela está com raiva?

Muito provavelmente, se assim o for, é porque ela fez um rápido mas complexo julgamento sobre o evento que, pelo menos, inclui a suposição a respeito dos motivos da pessoa - digamos que seja um homem -- que a empurrou: por exemplo, que sua ação teve a intenção de prejudicá-la e que ela não fez nada para merecer isso. Aristóteles (8.3.1380b16-18) nota que nós não respondemos com raiva quando nós erramos e estamos sofrendo justamente, pois, neste caso, a desconsideração não é inapropriada, como sua definição requer. Se a mulher em questão, subseqüentemente, conclui que o homen a empurrou por acidente, ela irá, com grande probabilidade, deixar de sentir raiva. Como Aristóteles observa na sua discussão sobre amabilidade ou mansidão, que ele trata como o contrário de raiva, uma desconsideração deve ser voluntária e as pessoas reagem moderadamente em relação 'as ofensas não intencionais ou em relação 'as pessoas que desejavam fazer o contrário do que elas de fato fizeram (2.3.1380a8-12).

Vamos supor que ela descubra que o homem a empurrou com a finalidade de salvar sua vida - digamos que ela estivesse no caminho de um carro que se aproximava. Nesse caso, ela não apenas não sente mais raiva, mas, certamente, em vez disso, sente gratidão. Ela pode responder fisicamente à rápida, embora atrasada, consciência do perigo com sintomas que se pareçam com aqueles associados à raiva - respiração rápida, aumento dos batimentos cardíacos - , mas, mais do que ira, o que ela sente é alívio. Ou, se as manifestações de raiva são justamente o que induz 'a emoção mesma (como William James argumentava de maneira conhecida), então, talvez, ela direcione essa raiva contra o motorista do carro.

Raiva, então, envolve um julgamento de intenções. Eis o porquê de nós normalmente não sentirmos raiva de pedras - isto é particularmente claro se, como Aristóteles, nós entendermos por raiva uma emoção acarretando um desejo de vingança que é acompanhado, como eu sugeri, de uma dor permanente, derivando de um insulto relembrado. Nós não ficamos furiosos com a pedra, por mais que doa bater nosso dedo nela, já que bater o dedo não é o mesmo que ser humilhado. Além das intenções dos outros, a raiva depende, também, dos próprios valores de uma pessoa, isto é, o que alguém considera 
como bom ou mau, desejável ou o contrário. Suponha que a mulher em nosso experimento mental soubesse que o carro estava se aproximando e tentasse cometer suicídio lançando-se 'a frente do carro. O homem, por empurrá-la, impediu-a de tirar sua vida. Ela está com raiva dele? Novamente, isso dependerá, em parte, se ou não ela acredita que ele estivesse consciente dos propósitos dela e deliberadamente os frustrou. Note como o mesmo ato e a mesma intenção que evocaram a gratidão da mulher na cena prévia agora despertam sua ira. A raiva depende, como Aristóteles estava consciente, de um intrincado e sutil conjunto de julgamentos; ela é qualquer coisa, exceto reflexo.

Na minha visão é concebível, embora improvável, que uma psicologia suficientemente refinada da raiva poderia ser capaz de separar todos os casos de raiva verdadeira - nos quais o sujeito levasse em consideração as intenções e outros fatores psicológicos e éticos - de outras emoções como também de outras reações instintivas tais como as que resultam das expressões de susto ou surpresa. Uma tal explicação da raiva seria, não obstante, crucialmente deficiente e não apenas porque lhe faltaria a descrição fenomenológica dos estados internos de consciência do sujeito. Em uma análise puramente física, os meios de aumentar ou diminuir a raiva se reduzem à manipulação de suas manifestações orgânicas: aumento ou decréscimo da pressão sangüínea, do ritmo cardíaco e assim por diante, bem como por meios químicos. Vamos assumir que esses meios podem ser eficazes. Permanece o caso em que eles não são exaustivos, pois outro modo de induzir ou eliminar a raiva - o modo de Aristóteles - é alterar a visão do sujeito em relação a uma ofensa e o contexto no qual ela ocorreu, inclusive a possibilidade de que ela fosse merecida. Mesmo se uma explicação cognitiva apenas complementa uma teoria física que é capaz de identificar ou controlar todas as reações que denominamos raiva, ela acrescenta uma dimensão essencial à pragmática da emoção. O caso é totalmente análogo àqueles das doenças psicossomáticas que respondem às intervenções tanto médicas quanto psicológicas.

\section{Raiva e insulto}

Seja como for, há um aspecto no qual minha história do homem empurrando a mulher é defeituosa como uma ilustração da teoria de Aristóteles sobre a raiva, pois o que é extraordinário sobre a análise aristotélica não é, apenas, o fato de ela incluir julgamentos a respeito de motivos e coisas semelhantes, mas é, também, o de ele limitar as causas da raiva às ofensas intencionais de um único tipo, que são reunidas sob o termo oligôria ou desconsideração. Aristóteles define uma desconsideração como "a atualização de uma opinião sobre algo que parece ser sem valor" (energeia doxês peri to mêdenos axion phainomenon, 2.2.1378b10-11). Ele especifica que nós consideramos 
coisas boas e más como dignas de esforço (spoudê), assim como qualquer coisa que contribua significativamente para elas; coisas que têm pouca ou nenhuma relação com elas são consideradas sem valor. Para termos uma idéia de quão severa esta restrição é, podemos considerar as três classes de desconsideração que Aristóteles enumera. A primeira é o desprezo ou kataphronêsis, que ele define como a crença de que alguma coisa não tem valor; segue-se, a fortiori, que nós desconsideramos aquilo que nós desprezamos, já que o desprezo é justamente a crença atualizada (ou agir sob a crença) de que uma coisa é, ou parece ser, sem valor. A segunda categoria de desconsideração é mais interessante. É o epêreasmos ou "despeito," que Aristóteles define como "bloquear os desejos [boulêseis] de outra pessoa não com a finalidade de ter alguma coisa para si mesmo, mas, principalmente, de que o outro não a tenha" (2.2.1378b18-19). O despeito, Aristóteles explica, repousa, precisamente em que o ofensor não busca vantagem pessoal. A única explicação para a frustração gratuita dos objetivos do outro, de acordo com Aristóteles, é que o indivíduo nem o teme nem busca sua amizade; ele, então, é considerado inútil, seja para o bem ou para o mal, o que para Aristóteles é, justamente, a definição de falta de valor.

Ao conectar essa última condição à definição de despeito, Aristóteles não está simplesmente buscando descrever uma forma de comportamento detestável e conhecida. Se alguém bloqueasse o desejo de outra pessoa por causa de algum interesse próprio, isso não apenas não constituiria um caso de puro despeito - como nós mesmos concordaríamos -, mas também não seria causa de raiva, o que pode parecer bem mais estranho para nós. Impedir a realização dos projetos de outra pessoa, ou causar dano a ela, não são razões, de acordo com Aristóteles, pelas quais as pessoas ficam enraivecidas. É assim, também, com a terceira categoria de desconsideração, a saber, insolência ou hybris. Novamente, essa é definida como falar ou agir de um modo que cause vergonha a outra pessoa, não porque alguma coisa possa acontecer ou porque aconteceu a você, mas pelo puro prazer de fazer isso (2.2.1378b23-25), que deriva de um sentimento de superioridade, não de alguma vantagem. Se o ultraje é em revide a uma injúria, isto não conta como insolência ou hybris, mas como vingança. Um pouco mais adiante, Aristóteles explica que nós temos a tendência de ficar enraivecidos com pessoas que riem, escarnecem ou zombam de nós, pois eles são insolentes conosco, e, de fato, com qualquer um que nos injurie (blaptontes) de algum modo que indique insolência; a afronta, Aristóteles repete, não deve ser nem em revide a alguma coisa nem vantajosa para aqueles que a infligem, pois somente assim ela parece ser em razão da insolência (2.2.1379a29-32), isto é, uma espécie de desconsideração, e, daí, um estímulo à raiva.

Alguém poderia supor que Aristóteles exclui a vingança ou castigo como uma causa da raiva com base no fato de que a vítima é consciente de que ela mereceu aquilo e, como Aristóteles diz, nós não ficamos enraivecidos quando percebemos que estamos 
sofrendo justamente. Mas, o que dizer do dano infligido em razão de vantagem pessoal? A linha de raciocínio aristotélica é claramente a mesma em ambos os casos: tirar desforra ou causar um dano em razão de alguma vantagem não denunciam em si mesmo a crença de que o alvo de um tal comportamento é sem importância, e, portanto, não contam como desconsiderações - que são as únicas bases da raiva. A raiva não é uma resposta para o dano, como tal, mesmo quando o dano é intencional. Qual emoção, então, se existe alguma, surge como resultado do sofrer uma injúria deliberada e não merecida? A resposta para Aristóteles é, eu acredito, o ódio ou a hostilidade (misein).

Aristóteles observa que se alegrar com o infortúnio de outro é sinal de inimizade ou de uma desconsideração de alguém a você (2.2.1379b17-19). Estas são as alternativas: pode-se esperar que um inimigo se delicie com sua ruína, sem acontecer que ele (ou ela) desdenhe de você como sendo de pouco valor. Quando um inimigo se comporta desse modo, por conseguinte, a pessoa não reage com raiva. De modo similar, Aristóteles nota que nenhuma pessoa desconsidera uma outra que ela teme (2.3.1380a22-23), porque o temor é um sinal da própria fraqueza de alguém e isso é incompatível com desprezo pelo outro. Conseqüentemente, nós não podemos ficar enraivecidos com aqueles que nos temem, embora possamos, certamente, não gostar deles. Contrariamente Aristóteles diz que "é impossível temer e ter raiva de alguém ao mesmo tempo" (2.3.1380a33). A razão para isso, eu suponho, é que nós reconhecemos, pelo nosso medo, que o outro tem mais força, e, por conseguinte, que ele está em uma posição melhor ou mais adequada para provocar uma desconsideração. Mas nós não gostamos de pessoas atemorizadoras (phoberoi), diz Aristóteles, pois "ninguém gosta [philei] de uma pessoa que teme" (2.4.1381b33). Nós nem mesmo retribuímos raiva com raiva, de acordo com Aristóteles, uma vez que aqueles que estão enraivecidos não parecem agir com desprezo pelos outros (2.3.138a.34-35; eles estão reagindo a um desdém), todavia a raiva é listada como uma das três primeiras causas da inimizade (2.4.1382a1-2).

A aguda distinção para a qual Aristóteles chama atenção entre raiva e ódio ou inimizade pode nos surpreender, mas ela é crucial para seu entendimento da raiva como uma emoção. A inimizade, de acordo com Aristóteles é o oposto da amizade ou afeição. Aristóteles tem uma visão radical do to philein: gostar de uma pessoa implica desejar coisas boas (ou o que alguém acredita serem coisas boas) em função única e exclusivamente do bem dela - não do próprio bem - e agir, por conseguinte, da melhor maneira possível (2.4.1380b35-1381a1). Um amigo (philos), Aristóteles continua, é alguém que ama e, em retorno, é amado, e aqueles que se consideram a si mesmos como mutuamente assim dispostos consideram-se a si mesmos como amigos (2.4.1381a1-3). Aristóteles conclui de suas definições que um amigo compartilha do 
prazer ou da dor do outro "por nenhuma outra razão a não ser as razões do outro" (2.4.1381a5-6). Assim, aquele que deseja ao outro as mesmas coisas que a si mesmo, parece ser um amigo.

Um inimigo, por sua vez, é identificado pelo oposto: ele deseja coisas ruins ou prejudiciais (kaka) ao outro. Aristóteles diz que a inimizade difere da raiva 'a medida que o intento (ephesis) da raiva é causar dor, enquanto o do ódio é infligir prejuízo (2.4.1382a8). Segue-se que, para uma pessoa com raiva, é importante que o outro perceba (aisthesthai) a reação (não existe uma tal coisa como dor não percebida), enquanto que para alguém que odeia é indiferente se um inimigo é consciente ou não do dano causado a ele. Nós podemos ver isso claramente em um exemplo extremo de prejuízo, quero dizer, a morte: quando odiamos alguém, diz Aristóteles, desejamos que ele ou ela não exista, mas quando estamos com raiva, desejamos que o outro sinta em troca (antipathein) a mesma coisa (dolorosa) que provocou nossa raiva (2.4.1382a1415). A morte, no entanto, o faria insensível 'a dor.

Raiva, nesse sentido, é um assunto pessoal. Como Aristóteles assinala, alguém pode sentir raiva somente de um indivíduo - de Cleon, por exemplo - e não de uma classe de pessoas ou da humanidade em geral (2.2.1378a34-35), enquanto ódio ou aversão podem ser dirigidos contra um grupo, por exemplo, ladrões em geral (2.4.1382a4-7). Faz sentido, então, que o ódio, assim entendido, não seja acompanhado por dor da mesma maneira que a raiva em relação a uma desconsideração específica deva ser. Embora o termo "ódio" (o "hate" em inglês) possa trazer a imagem de uma repugnância extrema que é mais palpável que raiva, para Aristóteles to misein significa mais precisamente um antagonismo estabelecido e constituído, que é duradouro e não está sujeito, como a raiva está, a ser curado pela passagem do tempo (2.4.1382a7-8).

No entanto, há um paradoxo aqui. Se o ódio não acarreta dor, como Aristóteles diz, ele pode ser qualificado como uma emoção na definição que Aristóteles oferece na Retórica, que estipula que as emoções devem ser acompanhadas de prazer ou dor 92.1.1378a21-22)? Eu estou inclinado a pensar que ambos, amor e ódio trazem dificuldades classificatórias para a psicologia de Aristóteles. Na Ética a Nicômaco, Aristóteles afirma que philia se parece com um estado de caráter firme ou hexis, uma vez que ela é acompanhada por uma escolha deliberada (proairesis), e ele cunha o termo philêsis - um "sentimento amoroso," talvez - para denotar o aspecto amoroso que corresponde ao pathos (8.5.1157b28-32). Prazer e dor não são componentes essenciais de uma hexis, assim não necessitam acompanhar a philia ou seu oposto, o ódio. Na Retórica, onde ambos são simplesmente incluídos entre os pathê (assim como eles são, também, na Etica a Nicômaco, 1105b21-23), talvez Aristóteles tenha suposto que o desejo (boulesthai) de 
que coisas boas aconteçam para um amigo (ou coisas ruins para um inimigo) fosse acompanhado pela phantasia de sua realização, exatamente como a orexis de vingança o é, no caso da raiva. Assim sendo, ambos, amor e ódio, cairiam sob a categoria de emoções prazeirosas, e isso explicaria por que o último não é acompanhado de dor. É menos provável, eu penso, que Aristóteles tivesse em mente o prazer que nós auferimos das boas coisas que acontecem com um amigo e da dor que experimentamos nas ruins, e viceversa no caso de um inimigo.

Nós determinamos, então, que uma desconsideração é dolorosa e que a dor persiste (com toda a probabilidade) durante a recordação ou o pensamento, até o momento em que a afronta é retribuída por meio do ato de vingança, que é eficaz somente se o outro sente, em retorno, a dor infligida. A vingança, então, deve ser análoga 'a desconsideração mesma, de modo que ela produza uma dor perceptível, e não apenas objetive prejudicar (por conseguinte ela não irá matar a pessoa). Quando alcançada, a vingança traz prazer, e elimina a dor, fruto da desconsideração, e, daí, a raiva (o prazer é antecipado enquanto a raiva estiver ativa). Presumivelmente, a vingança é de tal tipo que ela abole a crença existente na falta de valor de uma pessoa, demonstrando que tal pessoa não é inferior ou menos poderosa em relação a uma outra.

\section{O mundo da raiva}

Uma desconsideração, como vimos, consiste em uma palavra ou gesto que ativa uma crença ou doxa - isto é, manifesta a crença, na forma de um ato ou ergon de que alguém não tem valor. A reação necessária a tal ato é restaurar a opinião - da própria pessoa ou de outra - sobre seu próprio valor, por meio de um ato ou represália que demonstra a importância da pessoa em relação a uma outra (tirar a desforra [antipoiein] não é, em si mesmo, arrogância, mas recompensa (2.2.1378b25-26). A raiva é justamente o desejo de restaurar a situação anterior ao insulto (ou, por sua vez, depreciar o ofensor). Mas nem toda desconsideração inspira raiva. É hora de voltar ao dispositivo, incluso na definição aristotélica de raiva, de que o autor da desconsideração seja alguém que não deveria tê-la feito.

O mundo subentendido pela explicação aristotélica de raiva é hierárquico, constistuído de pessoas que são superiores ou inferiores em relação à força, à riqueza, ao status e a coisas semelhantes. A questão da hybris, por exemplo, é a de demonstrar a superioridade de alguém em relação a um outro; portanto, ela é característica dos ricos e, também, dos jovens (2.2.1378b28), que, provavelmente são fisicamente fortes 
e, ao mesmo tempo, necessitam provar isso eles mesmos. Essa é a razão pela qual as pessoas que têm dúvidas sobre elas mesmas, sejam em relação à aparência ou à ocupação, ou a qualquer coisa que elas considerem importante, são inclinadas a sentir raiva, enquanto aquelas que são confiantes no fato de que elas se sobressaem (huperekhein) não o são (2.2.1379a36-1379b2). Pessoas que realmente se sobressaem, seja em relação à família, ao poder, à riqueza, ou, de fato, a qualquer habilidade, como a oratória (que aqui está estreitamente ligada à habilidade de governar), esperam deferência (poluôreistai) de seus inferiores (hêttontes) em razão de sua superioridade (2.2.137b341379a6), e são particularmente suscetíveis a se tornarem enraivecidas se, em lugar disso, sofrem alguma desconsideração. Do mesmo modo, nós também tendemos a sentir raiva daqueles que se opõem a nós - se eles são inferiores, ou não nos retribuem com gentileza, como se, ao contrário, fôssemos seus inferiores - e, acima de tudo, sentimos raiva em razão de alguma desconsideração recebida de pessoas sem valor (en mêdeni logôi), pois, como Aristóteles diz, "nós assumimos que a raiva por causa de uma desconsideração é dirigida àqueles que não devem [prosêkontes] agir assim, e inferiores não devem desconsiderar seus [superiores]" (2.2.1379b11-13).

Poderíamos descrever a situação social na qual a raiva é engatilhada ou aplacada na explicação aristotélica como sendo moldada por um agudo senso de honra, com sua intensa consideração pelo status, protocolos de conduta, e opinião dos outros -Aristóteles especifica, por exemplo, que nós estamos mais dispostos a sentir raiva quando a desconsideração ocorre na presença daqueles com quem competimos, daqueles que admiramos ou por quem gostaríamos de ser admirados ou daqueles diante dos quais sentimos vergonha ou que sentem vergonha diante de nós (2.2.1379b24-26). Aristóteles mesmo diz que o desrespeito (atimia) é uma parte da hybris e que desonrar (atimazôn) uma pessoa é desconsiderá-la, pois o que é sem importância não tem valor (timê), seja para o bem ou para o mal (2.2.1378b29-31). Ele cita como ilustração as palavras de Aquiles em relação a Agamêmnon: "ele desonrou-me," e tratou-me como se eu fosse "um desprezível [atimêtos] vagabundo" (Iliada 1.356, 9.648, etc.). A alusão a Homero sugere, eu penso, que o uso da palavra timê no contexto do desprezo e da raiva pode ter tido uma reverberação poética, uma vez que na prosa o termo se referia principalmente aos direitos e cargos políticos ou ao valor econômico. Mas honra captura bem a extrema sensibilidade que Aristóteles reporta em relação às ofensas contra a dignidade e a estima de alguém aos olhos dos seus companheiros, contanto que nós não assimilemos a idéia ao complexo de honra e vergonha que se tornou popular na assim chamada antropologia mediterrânea nas últimas duas ou três décadas, com sua particular ênfase na necessidade do controle do comportamento sexual das mulheres na família de al- 
guém. A literatura ateniense do período clássico oferece pouca evidência de uma obsessiva preocupação com a desonra nesse sentido estreito de violação.

Embora a causa da raiva seja uma desconsideração que requer uma satisfação da parte de alguém que não deveria tê-la feito, tal como um subordinado, um amigo ou beneficiário, de quem seria esperado ter mais cuidado com a dignidade da outra pessoa, Aristóteles reconhece que existem certas situações nas quais nós estamos mais suscetíveis ou não a tais afrontas, independentemente de sua fonte. Quando nós estamos nos divertindo em uma festa ou nos sentindo particularmente prósperos, nós não estamos inclinados a sentir raiva (2.3.1380b2-5). Contrariamente, ficamos mais irritadiços quando estamos sofrendo (lupoumenos, 2.2.1379a11) por causa de algo que queremos ou que nos falta e somos particularmente inclinados a sentir raiva daqueles que obstruem o preenchimento de nosso desejo, como quando estamos com sede, doentes, apaixonados, passando necessidade etc. Pode ser que nossa condição de carência exponha-nos mais ao insulto, justamente na exata medida em que uma pessoa deixa de respeitar nossa necessidade, mas, mesmo que isso possa ocorrer, é importante distinguir entre o sofrimento que resulta da falta, como a sede, a doença, a pobreza, e outras coisas, e a dor que acompanha a raiva. A dor de um tipo nos faz mais susceptíveis, talvez, a sentir a outra dor, mas as duas têm causas diferentes nesse caso e não são a mesma dor.

A raiva para Aristóteles, então, é qualquer coisa exceto um reflexo da dor ou prejuízo, mesmo quando a causa é intencional. Aristóteles vislumbra um mundo no qual a auto-estima depende da interação social: no momento em que a opinião negativa sobre o valor de alguém é atualizada publicamente na forma de uma desconsideração, a pessoa perde crédito e o único recurso é um ato compensatório que restaure sua posição social. A raiva é exatamente o desejo de reajustar as coisas no seu lugar - é o correlativo interno para a perda pública de respeito. Quanto a isso, a visão aristotélica de raiva assenta bem com o conjunto das emoções que ele escolheu discutir na Retóri$c a$, do qual o inventário derivado da lista de meus alunos se diferencia de modo tão notável.

Tradução integral

MARIA CECÍLIA DE M. N. COELHO** Faculdade de Filosofia, Letras e Ciências Humanas da Universidade de São Paulo 


\section{Notas}

* Professor Doutor do Departamento de Estudos Clássicos da Brown University.

** Doutoranda em Grego do Programa de Pós-Graduação em Letras Clássicas da FFLCHUSP.

\section{Agradecimentos}

Agradeço a Maria Cecília de M. N. Coelho pela tradução deste texto, que foi apresentado na Universidade de São Paulo em junho de 2000. Esse artigo foi originalmente concebido em ingles para o colóquio "Mênin aeide thea: Aspects of Anger in Antiquity" (Heidelberg, Setembro de 1999). Gostaria de agradecer aos organizadores desse evento, Susanna Braund e Glenn Most, por sua permissão para publicar esta versão portuguesa. Uma outra, mais longa, com notas e bibliografia, constará das atas do Colóquio.

KONSTAN, David. Anger and emotions in Aristotle. Strategies of status. ABSTRACT: This paper intends to discuss the aristotelic idea of anger developed in Rhetoric, book two, and its correlation at the philosopher's theory of emotions.

KEY WORDS: Aristotle; Rhetoric; theory of emotions. 